6 OPEN ACCESS

\title{
Pictorial health warnings and wear-out effects: evidence from a web experiment in 10 European countries
}

\author{
Eva Woelbert, ${ }^{\oplus}$ Béatrice d'Hombres ${ }^{\circledR}$
}

\begin{abstract}
- Additional material is published online only. To view, please visit the journal online (http://dx.doi.org/10.1136/ tobaccocontrol-2018-054402).

European Commission, Joint Research Centre (JRC), Ispra, Italy
\end{abstract}

\section{Correspondence to} Dr Béatrice d'Hombres, Modelling, Indicators \& Impact Evaluation Unit, Joint Research Centre, European Commission, Ispra 21027, Italy.; beatrice.dhombres@ec.europa. eu

Received 29 March 2018 Revised 12 October 2018 Accepted 31 October 2018 Published Online First

4 January 2019

\begin{abstract}
Objective This paper examines whether there are possible wear-out effects associated with repeated exposure to pictorial health warnings on tobacco products. Wear-out effects can be general, that is, people get used to the presence of pictorial warnings in general, or specific to the content of the warnings (ie, the images used). Distinguishing between these two types of wearout is important for understanding how to maintain the effectiveness of health warnings over time.
\end{abstract}

Methods This study used data from two surveys carried out in 10 European countries. Participants $(n=12600)$ were exposed in a random order to a series of health warnings and assessed the salience of the warnings as well as their effects on smoking intentions. Using these data and country variations in health warning legislation, we tested whether warning pictures are subject to general and/or specific wear-out effects.

Results Responses were stronger to combined text+picture warnings than to text-only warnings. This effect was lower for smokers living in countries where combined warnings were already in place at the time of the data collection, compared with smokers residing in countries where text-only warnings were in use. This result, observed for combined warnings with new pictures, is in line with the presence of general wear-out effects. Combined warnings with an unknown pictorial content were more effective than those including pictorial warnings already in use, suggesting that specific wear-out effects are also at play.

Conclusions These findings strengthen the evidence that pictorial health warnings are an effective tool for tobacco control policies and suggest that, even in the presence of a general wear-out effect among smokers, periodically introducing new pictures helps to maintain warning effectiveness over time.

\section{INTRODUCTION}

Warning labels on tobacco packaging are a cost-effective way of warning citizens about the dangers of tobacco and of discouraging smoking. Warning labels on packages impose minimal costs on public health budgets, and ensure a maximum exposure of the target group to the warnings. Smokers and at-risk individuals frequently interact with tobacco packaging-a heavy smoker sees warning labels on cigarette packets an estimated 7300 times per year. ${ }^{1}$ The WHO Framework Convention on Tobacco Control (FCTC) ${ }^{2}$ mandates that all tobacco packages should carry large health warnings and suggests combining text warnings with pictures. ${ }^{3}$ Pictures on health warnings are meant to illustrate the adverse effects of smoking-often showing diseased body parts or surgical procedures. Several studies have shown that the addition of a picture to the text warning has increased the effectiveness of tobacco health warnings, even though the effect seems to be short-lived. ${ }^{4-7}$ To date however, there is limited evidence to inform policy makers on how to maintain the effectiveness of pictorial warnings over time.

This paper examines if pictorial tobacco health warnings are subject to wear-out effects. Wear-out effects can be general, that is, people get used to the presence of pictorial warnings, or, specific to the content of the warnings (ie, the images used). The FCTC recommends rotating and/or replacing the content of the health warnings in order to minimise wear-out effects. This recommendation assumes that, while specific warnings will lose effectiveness over time, replacing the warning content will counteract this effect. However, the empirical evidence to guide this recommendation is missing. While some observational studies have documented that warning effectiveness decreases over time, ${ }^{4-7}$ it is not clear whether periodically changing the content of the warnings would help maintain the effectiveness of the warnings over time, or whether the documented decrease in responsiveness is due to a general wear-out of pictorial warnings.

In Europe, between 2003 and 2016, pictorial health warnings were optional. Each pack of cigarettes had to contain a general health warning covering $30 \%-35 \%$ of the front surface as well as one additional health warning, linked to specific health consequences of smoking, covering $40 \%-50 \%$ of the back of the packets of cigarettes. The health text warning on the back of the packets of cigarettes were to be selected from a set of 14 agreed text messages. ${ }^{8}$ Member States were free to decide whether or not to add pictures to the text warnings. If pictures were added, these had to be taken from a library containing 42 pictures. $^{9}$

The present study used data from two similar surveys carried out in 10 European countries, exploiting differences across countries in the health warning legislation to test for general and specific wear-out effects. At the time of the data collection, four of the countries used text-only warnings (TWs) (henceforth 'text countries'), whereas the other six countries had combined text+picture warnings (PWs) in place (henceforth 'picture countries').

Throughout the paper, we estimated the added value of pictures by comparing combined PW warnings with TWs with the same text contents. We tested for the presence of a generalised wear-out effect, independent of the content of the warnings, by comparing the added value of pictures across countries with differing labelling legislation. We, then, examined whether there are specific wear-out 
effects and the potential benefit of regularly changing the pictorial content of health warnings.

Two conceptually defined outcome variables were considered in the study, namely the salience of the health warning, and its effect on smoking intentions. There appears to be little consensus in the literature as to what are the best proxy variables for measuring warning effectiveness. In some studies, a large set of variables are analysed individually, ${ }^{4} 10$ whereas other studies aggregate measures of specific constructs, ${ }^{11}{ }^{12}$ compute an overall measure of warning impact ${ }^{13-15}$ or use perceived general effectiveness. $^{16}$

Using smoking intentions is motivated by the fact that one key purpose of health warnings is to encourage non-smokers to avoid smoking and smokers to quit smoking. ${ }^{217}$ Salience is relevant because attracting attention is meant to increase the likelihood that viewers engage with the health warning. ${ }^{18-20}$ Moreover, attention is particularly relevant in the context of habituation and wear-out. ${ }^{21}$

\section{METHODS}

\section{Sample}

The paper used data from a large-scale web experiment embedded in two similar surveys. The data collection was funded by the European Commission in the context of the revised Tobacco Products Directive, ${ }^{22}$ with the purpose of selecting suitable pictures to be associated with the 14 smoking-related text warnings, which were then rolled out in 2016 . Six potential pictures to be associated with each text warning were tested. The study was commissioned to a consortium. ${ }^{\mathrm{i}}$ The data were collected in two similar surveys, which we analysed jointly. Both surveys were administered online and were carried out in 10 European countries: Belgium (BE), Germany (DE), Denmark (DK), Spain (ES), France (FR), Italy (IT), Poland (PO), Romania (RO), Sweden (SE) and the United Kingdom (UK). All respondents were contacted by email and provided informed consent. They were compensated for participation with a fixed fee of $€ 5 .^{23}$

The data collection for the first survey took place in November 2012, with a sample size of 800 respondents per country. Data for the second survey were collected in January 2014, with a country sample size of 460 respondents. .i $^{\text {The samples were }}$ randomly drawn from international online panels representative of the online population in each country between 18 and 65 years of age. ${ }^{\text {iii }}$ However, since younger respondents were of particular interest, the 18-30 age group was oversampled.

\section{Design of the web experiment}

After completing questions on sociodemographics and smoking status, respondents were exposed to a series of up to seven health warnings in random order, and rated each warning with respect to cognitive and emotional reactions as well as behavioural intentions. Each respondent was exposed to one TW, which was randomly selected from the 14 possible

\footnotetext{
${ }^{\mathrm{i}}$ The consortium was composed of the London School of Economics, Tech4i2. Limited, Block de Ideas, and Universitat Overta de Catalunya. Specific Contract No 17.02020017.030600/12/626060/SANCO.D.4 implementing Framework Contract No EAHC/2011/CP/01/LSE.

${ }^{i i}$ Note that some respondents were dropped from both surveys because of some irregularities in the data reducing the sample size by around $8 \%$.

iii The panel was drawn via the provider http://www.cint.com/. Information on the response rate or characteristics of non-responding individuals was not available to the authors.
}

texts. In addition, participants in the first survey saw six combined PW, while those in the second survey were exposed to four PW. Each PW was drawn in two steps as follows: first, one of the 14 possible TWs was randomly drawn from a uniform distribution without replacement. Then, one of the six candidate pictures for this specific TW was drawn, and the combination of the two formed the PW. All pictures, but one, were new for all respondents. ${ }^{\text {iv }}$ Details on the stimulus material and the randomisation procedure are described in online supplementary appendix A. ${ }^{v}$

\section{Dependent variables}

'Salience' was measured by the following question: 'please indicate to what extent this warning catches your attention'. The 'quit/avoid' variable was measured by two items. The question for the smokers was: 'please indicate whether this image motivates you to quit smoking' while, for never-smokers and ex-smokers, the framing of the questions was the following 'please indicate whether this image motivates you to avoid smoking'. The answers to these two items were combined to derive a single 'quit/avoid' variable. The two outcome variables were measured on a continuous scale, ranging from 1 (not at all) to 7 (very much), using a slider.

\section{Analyses}

All data processing and analyses were performed using Stata V.13. To account for repeated measurements due to the same individual being exposed to different stimuli, we employed random intercept models. ${ }^{24}{ }^{25}$ We accounted for possible further dependencies using individual cluster-robust SEs. ${ }^{26}$

\section{Estimating the added value of pictures}

This paper focuses on the added value of pictures by comparing $\mathrm{PW}$ with TW, and examines whether this added value is subject to wear-out effects. We first measured the added value of PW by estimating the following equation:

$$
y_{i w h c}=\alpha_{i}+\beta W_{w h}+H_{b}+C_{c}+\varepsilon_{i w h c}
$$

where $y_{i w h c}$ is the self-reported response of participant $i$ living in country $c$ to the warning $w$ with a text content $h, W_{w b}$ is a treatment variable taking the value one if the warning is a PW and zero if the warning is a TW. $H_{b}$ is a set of specific text content dummies and $C_{c}$ are country dummies while $\alpha_{i}$ is the random individual intercept and $\varepsilon_{i w b c}$ the error term. The key parameter of interest is $\beta$, which measures the incremental effect of PW over TW with the same text content. More specifically, the inclusion of $H_{b}$ implies that only variations between warnings of a given text content are used to identify $\beta$. Without $H_{b}$, the interpretation of $\beta$ would be slightly different. It would provide a consistent estimate of the impact of PW over TW, irrespective of the warning content. The randomised design ensured that it was not necessary to add in Equation (1) any additional covariates to obtain consistent estimates of $\beta$, but in online supplementary appendix $\mathrm{C}$ we report the results obtained when including individual covariates, and accounting for the censored nature of the dependent variables.

\footnotetext{
iv Only one of the pictures was used in the 'picture countries' at the time of the surveys.

${ }^{v}$ For additional information on the dataset, see a recently published study by the contractors. ${ }^{23}$
} 
Testing for a general wear-out effect

We tested for a general wear-out effect of combined warnings by examining if the added value of pictures varied across countries with differing labelling legislations. Specifically, we hypothesised that respondents living in 'picture countries' may react less to PW than individuals living in 'text countries'. We tested for this by allowing the coefficient $\beta$ to differ for the two types of countries. Formally, equation (1) was expanded as follows:

$$
y_{i w h c}=\alpha_{i}+\beta^{t} T_{c} W_{w h}+\beta^{p} P_{c} W_{w h}+H_{b} C_{c}+\varepsilon_{i w h c}
$$

where $T$ is a dummy variable equal to one for the text countries and $P_{c}$ is equal to one for the picture countries. The coefficients $\beta^{t}$ and $\beta^{p}$ measure the impact of PW over TW in the two groups of countries while $\beta^{t}-\beta^{p}$ informs about a possible general wear-out effect. Given the fact that we estimated the added values of PW over TW, we already controlled for any differences across countries that would affect the effectiveness of TW and PW equally. We estimated equation (2) separately for smokers and non-smokers. Since smokers interact with cigarette packs on a daily basis, they are much more exposed to the warnings than non-smokers. Should there be a generalised wear-out effect, then we should observe it mainly on the subsample of smokers. To estimate equations (1) and (2), we removed from the sample the responses corresponding to the only picture that was in use in the 'picture countries' (DK, UK, FR, ES, RO and BE) at the time of the surveys. ${ }^{27}$

\section{Testing for content-specific wear-out effect}

This dataset also provides an opportunity to directly test the benefits of periodically introducing new pictures. In the analyses discussed above, contrasting $\beta_{p}$ with $\beta_{t}$ is informative about general wear-out, but does not tell us whether the new pictures tested in the survey elicit stronger responses than what would be achieved by showing pictures already known by the respondents. However, the dataset also contains responses to one picture that was part of the old set of PW and was thus not new to participants living in picture countries.

The 'known' picture was shown in the second survey, and was one of three pictures illustrating the text 'smoking damages your lungs'. For this analysis, we restricted the data to a subsample of observations from the second survey, referring to this specific TW and associated PWs. It is important to note that simply comparing responses across different pictures would not be informative here, as it would be confounded with any picture-specific differences. Instead, we drew on the richness of the dataset and employed a difference-in-differences approach. More specifically, we tested for a possible content-specific wear-out effect by extending equation (1) as follows:

$$
y_{i w c}=\alpha_{i}+\left(\beta^{t a} A_{w}+\beta^{t n} N_{w}\right) T_{c} W_{w}+\left(\beta^{p a} A_{w}+\beta^{p n} N_{w}\right) P_{c} W_{w}+C_{c}+\varepsilon_{i w h c}
$$

where $A_{w}$ is equal to one if the pictorial warning was part of the previous library and zero otherwise, while $N_{w}$ is equal to one for new pictures, zero otherwise.

$\Delta_{p}=\beta^{p n}-\beta^{p a}$ measures the difference between the new and used pictures for respondents from picture countries. Any difference between $\beta^{p a}$ and $\beta^{p n}$ might be driven by the novelty of the unknown pictures, but might equally be driven by the fact that some pictures elicit stronger responses than others. In contrast, $\Delta_{f}=\beta^{t n}-\beta^{t a}$ measures the difference between the new and used pictures for respondents living in text countries. Respondents living in those countries were equally unfamiliar with all of the pictures. Thus, this latter difference reflects only the picture-specific differences. Assuming these picture-specific differences are homogeneous across
Table 1 Sample characteristics from the two surveys (time of data

\begin{tabular}{|c|c|c|c|}
\hline & Full sample & Picture countries & $\begin{array}{l}\text { Text } \\
\text { countries }\end{array}$ \\
\hline & $(n=11849)$ & $(n=7078)$ & $(n=4771)$ \\
\hline \multicolumn{4}{|l|}{ Demographics } \\
\hline Age (mean) & 39.6 & 39.5 & 39.6 \\
\hline Female (\%) & 52.1 & 52.9 & 50.9 \\
\hline Married (\%) & 43.3 & 43.4 & 43.1 \\
\hline Family size (mean) & 3.1 & 3.1 & 3.0 \\
\hline \multicolumn{4}{|l|}{ Education } \\
\hline $\begin{array}{l}\text { Primary/ } \\
\text { secondary education (\%) }\end{array}$ & 57.8 & 54.7 & 62.4 \\
\hline Tertiary education (\%) & 42.2 & 45.3 & 37.6 \\
\hline \multicolumn{4}{|l|}{ Smoking status } \\
\hline Regular (\%) & 25.8 & 25.9 & 25.7 \\
\hline Occasional (\%) & 10.9 & 9.8 & 12.5 \\
\hline Ex-smoker (\%) & 16.8 & 17.0 & 16.5 \\
\hline Never smoker (\%) & 46.5 & 47.2 & 45.3 \\
\hline
\end{tabular}
collection: November 2012 and January 2014)

Information on smoking status is self-reported. Respondents could declare to be (i) smoker, (ii) social/special occasions smoker, (iii) ex-smoker or (iv) non-smoker. 'Picture countries' (DK, UK, BE, FR, ES and RO) are countries where combined text+picture warnings on packs of cigarettes were mandatory at the time of data collection, while 'text countries' are the countries where text-only warnings were in use (SE, DE, IT, PL). Statistically significant differences between the two groups of countries are reported in italic. See table 7 in online supplementary appendix B for country-specific summary statistics.

BE, Belgium; DE, Germany; DK, Denmark; ES, Spain; FR, France; IT, Italy; PO, Poland; RO, Romania; SE, Sweden; UK, United Kingdom.

the country groups, $\Delta_{p}-\Delta_{t}$ then measures the added value of introducing new pictures in picture countries.

\section{RESULTS}

\section{Descriptive statistics}

Table 1 displays summary statistics for the full sample as well as separately for the two groups of countries. Self-reported regular and occasional smokers made up $36.7 \%$ of the full sample.

Table 2 displays the unconditional averages of the two outcome variables when respondents are confronted to PW and TW. On average, PW were rated higher than TW, and

Table 2 Average rating of PW and CW

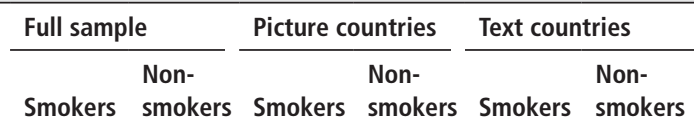

\begin{tabular}{ccccccc}
\hline PW & & & & & & \\
Salience & 4.64 & 5.07 & 4.57 & 5.06 & 4.72 & 5.09 \\
$\begin{array}{l}\text { Quit/Avoid } \\
\text { TW }\end{array}$ & 3.87 & 4.91 & 3.79 & 4.87 & 3.98 & 4.99 \\
Salience & 3.80 & 4.13 & 3.77 & 4.10 & 3.85 & 4.16 \\
Quit/avoid & 3.23 & 4.17 & 3.21 & 4.14 & 3.26 & 4.22
\end{tabular}

'Picture countries' (DK, UK, BE, FR, ES and RO) are countries where combined PWs on packs of cigarettes were mandatory at the time of data collection, while 'text countries' are the countries where TWs were in use (SE, DE, IT, PL). The sample of non-smokers includes both ex-smokers and respondents having never smoked. Both outcome variables are measured on a continuous scale, ranging from 1 (not at all) to 7 (very much), using a slider. See figure 2 in online supplementary appendix B for distributions.

BE, Belgium; DE, Germany; DK, Denmark; ES, Spain; FR, France; IT, Italy; PO, Poland; $\mathrm{PW}$, text+ picture warning; RO, Romania; SE, Sweden; TW, text-only warning; UK, United Kingdom. 
Table 3 Added value of pictures: combined vs text-only warnings

\begin{tabular}{|c|c|c|c|c|c|c|}
\hline & \multicolumn{3}{|l|}{ Salience } & \multicolumn{3}{|c|}{ Quit/avoid } \\
\hline & (1) & (2) & (3) & (4) & (5) & (6) \\
\hline & $\begin{array}{l}\text { Full } \\
\text { sample }\end{array}$ & Smokers & $\begin{array}{l}\text { Non- } \\
\text { smokers }\end{array}$ & $\begin{array}{l}\text { Full } \\
\text { sample }\end{array}$ & Smokers & $\begin{array}{l}\text { Non- } \\
\text { smokers }\end{array}$ \\
\hline \multirow[t]{2}{*}{$\hat{\beta}$} & $0.92^{* * *}$ & $0.85^{* * *}$ & $0.96^{* * *}$ & $0.73^{* * *}$ & $0.67^{* * *}$ & $0.77^{* * *}$ \\
\hline & $(0.02)$ & $(0.02)$ & $(0.02)$ & $(0.02)$ & $(0.02)$ & $(0.02)$ \\
\hline Observations & 73309 & 26880 & 46429 & 73308 & 26880 & 46428 \\
\hline
\end{tabular}

Equation (1) was estimated using an individual random intercept model with SEs clustered at the individual level. Additional covariates include a set of specific text-content dummies and country dummies. SEs are reported in parentheses. Stars denote statistical significance: ${ }^{*} p<0.05,{ }^{* *} p<0.01,{ }^{* * *} p<0.001$.

non-smokers showed stronger responses than smokers. Table 8, in online supplementary appendix B, reports some indicators of nicotine dependence for smokers and ex-smokers. No systematic differences emerge between picture and text countries in terms of the smokers' and ex-smokers' characteristics.

\section{The added value of pictures}

Table 2 shows the overall effectiveness of PW relative to TW on the full sample as well as on smokers and non-smokers separately. The results suggest that pictures had an added value, both in terms of salience and motivation to quit/avoid smoking. The average values of the salience and quit/avoid indicators, after having been exposed to a TW, were respectively equal to 3.8 and 3.2. Given the estimated value of $\hat{\beta}$ (table 3), the addition of pictures (PW) corresponds to an increase in effectiveness of health warnings by $24 \%$ and $23 \%$ for the two indicators, respectively.

Columns (2-3) and (5-6) show that these findings held true both for smokers and non-smokers, but the effect appears to be somewhat stronger for non-smokers.

\section{General wear-out and sustained effectiveness}

Comparing the effect of PW across picture and text countries can reveal if the added value of the picture is different in countries that have already introduced PW, relative to those that have not yet implemented this policy (see table 4). PW invoked stronger responses than TW in both types of countries, with $\hat{\beta}^{t}$ and $\hat{\beta}^{p}$ being significantly different from zero both for smokers and non-smokers. For salience, the difference between picture and text countries $\left(\hat{\beta}^{t}-\hat{\beta}^{p}\right)$ was not significantly different from zero on the full sample or for the subsample of non-smokers. However, a positive and significant difference for the smokers suggests that PW were more effective in text countries than in picture countries. Regarding smoking intentions, the difference in the impact of PW over TW between the two types of countries was positive and significantly different from zero on the full sample. However, the separate analysis for smokers and non-smokers reveals that this difference was primarily driven by smokers, and there was no significant difference across these two types of countries for non-smokers.

\section{Content-specific wear-out and the value of new pictures}

To test the benefit of periodically introducing new pictures, we conducted a difference-in-differences analysis by estimating equation (3). Table 5 reports the estimated value of $\hat{\Delta}_{p}-\hat{\Delta}_{t}$, that is, the estimated added value of introducing new pictures in the picture countries, while controlling for picture-specific differences. Table 9 in online supplementary appendix B displays the full details with estimates of $\beta^{p n}, \beta^{p a}, \Delta_{p}, \beta^{t n}, \beta^{t a}$ and $\Delta_{t}$. Results in table 5 suggest that, $\hat{\Delta}_{p}-\hat{\Delta}_{t}$, although positive, was not significantly different from zero in the subsample of non-smokers. However, when equation (3) was estimated on the subsample of smokers, $\hat{\Delta}_{p}-\hat{\Delta}_{t}$ was positive and significantly different from zero for both salience $(\mathrm{p}<0.10)$ and smoking intentions $(\mathrm{p}<0.05)$.

This result is in line with the existence of a specific wear-out effect. After having controlled for picture-content specific effects, PW with an unfamiliar pictorial content have a higher added value than those including a picture already known to the respondents.

\section{Robustness checks}

The conclusions are the same when including additional covariates and when accounting for the censoring nature of the outcome variables (see online supplementary appendix C). The confidence intervals of the estimated coefficients were generally smaller, thus confirming the robustness of the findings.

\section{DISCUSSION}

Applying a strictly randomised protocol on a large sample from 10 different European countries, results show that pictures

Table 4 General wear-out effect: combined vs text-only warnings, by country type and smoking status

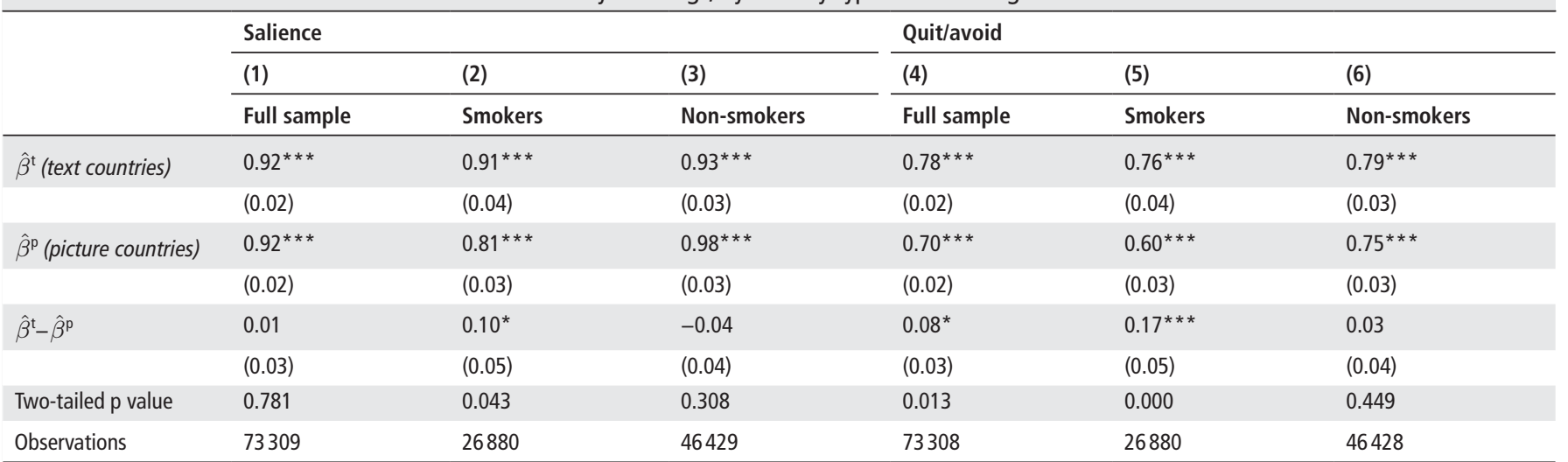

Equation (2) was estimated using an individual random intercept model with SEs clustered at the individual level. Additional covariates include a set of specific text-content dummies and country dummies. SEs are reported in parentheses. $\hat{\beta}^{\mathrm{t}}$ indicates the impact of PW, relative to TW, in text countries, while $\hat{\beta}^{\mathrm{p}}$ indicates the added value of PW over TW in picture countries. The bottom part of the table reports the difference between the two coefficients and tests if this difference is significantly different from zero. Stars denote statistical significance: ${ }^{*} p<0.05,{ }^{* *} p<0.01,{ }^{* * *} p<0.001$ 
Table 5 Content-specific wear-out effect

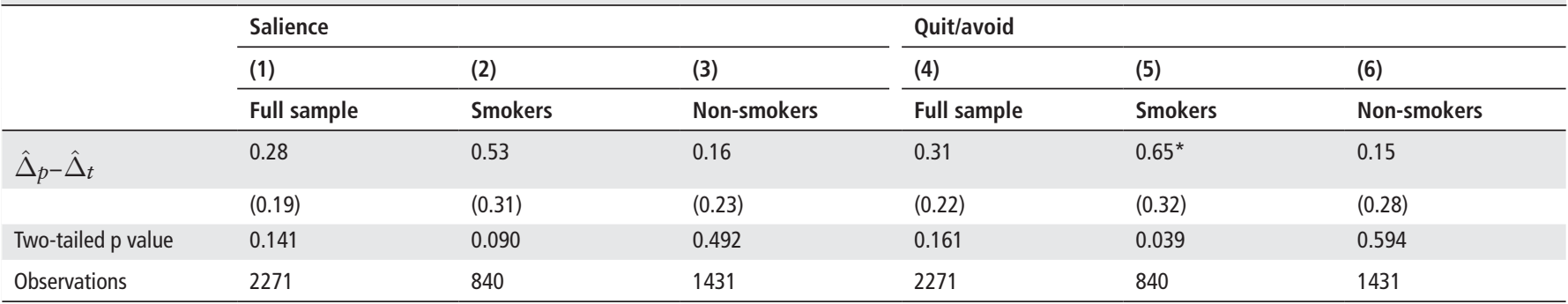

Equation (3) was estimated on a subset of observations using an individual random intercept model with SEs clustered at the individual level. Additional covariates include a set of country dummies. SEs are reported in parentheses. $\hat{\Delta}_{p}-\hat{\Delta}_{t}=\left(\hat{\beta}^{\text {pn }}-\hat{\beta}^{\text {pa }}\right)\left(\hat{\beta}^{\text {tn }}-\hat{\beta}^{\text {ta }}\right)$ is the difference-in-differences between the new and the old pictures, across the two country types. Stars denote statistical significance: ${ }^{*} p<0.05$, ${ }^{* *} p<0.01$, ${ }^{* * *} p<0.001$.

significantly add to the effectiveness of health warnings, both for smokers and non-smokers. This corroborates several observational as well as experimental studies on the effectiveness of pictorial warnings. ${ }^{11728}$

In countries that had already been using combined warnings at the time of the data collection, the added value of pictures was found to be significantly attenuated among smokers, but not for non-smokers. Although all pictures used in this analysis were new to all respondents, smokers from picture countries were already used to seeing PW on packets of cigarettes. Non-smokers on the other hand do not regularly interact with tobacco packaging and are hence not regularly exposed to pictorial health warnings. Thus, this finding suggests that - to a certain extentsmokers get used to the presence of pictures on health warnings in general. This explanation is in line with the finding that smokers in the UK actively divert their attention away from pictorial warnings, ${ }^{21}$ and could explain why the annual rotation of warnings in Australia did not appear to slow down a decrease in warning effectiveness. ${ }^{12}$ While some studies have documented the decreased effectiveness over time of a given set of warnings, ${ }^{5-7}$ to the best of our knowledge, this study is the first to provide evidence of a general wear-out effect.

By combining country differences in terms of labelling requirements with a difference-in-differences approach, we also found that PW with unfamiliar pictorial content had a higher added value. We argue that this result is in line with the existence of a specific wear-out effect. Taken together, these findings align with the literature on habituation, which found that the response attenuation after repeated exposure is partly stimulus-specific, and generalises to some extent to similar stimuli. ${ }^{29}$ Despite the general decrease in effectiveness associated with repeated exposure to PW, there is an added value in replacing the stimulus material. This finding supports the recommendation of WHO FCTC Article 11 to rotate health warnings. ${ }^{23}$

It is however important to consider alternative interpretations to our results. First, the finding that smokers in picture countries responded less to pictorial warnings could also be driven by the fact that these smokers are a selection of people less responsive to $\mathrm{PW}$, since they smoke in spite of the presence of PW. However, we estimated the added-value of PW over TW which implies that this selection sample bias should affect the responsiveness to PW relative to TW. If our findings were driven by sample selection rather than wear-out, we would expect a difference for smokers, and a difference in the opposite direction for non-smokers, which is not what we observe. Furthermore, smokers and ex-smokers were not systematically different across the two types of countries (see online supplementary appendix B3). While we cannot rule out the possibility that the difference across the two types of countries is in part driven by the fact that the policy has influenced the composition of the sample of smokers, neither the results for non-smokers, nor the comparison of indicators for nicotine dependence lend support to this interpretation. Second, the fact that the PW had a lower added value in picture countries than in text countries could be due to a greater effectiveness of TW in picture countries. The unconditional averages of the two outcome variables reported in table 2 do not support this hypothesis. Indeed, PW invoked lower responses in picture countries than in text countries and this difference was statistically different from zero, while, on the contrary, the rating of TW did not significantly differ between the two groups of countries. Finally, it is important to note that our analysis of content-specific wear-out relied on a small subset of the data. Thus, additional research on the relative magnitude of general versus specific wear-out is needed to confirm this finding.

Future research should also consider how changing other features of tobacco packaging might counteract wear-out effects, such as modifying layout and size of warnings, and adopting plain packaging. A recent study has shown that, in Australia, since the introduction of plain packaging, although the attention to combined warnings has declined over time, the cognitive and behavioural responses to the combined warnings have increased

What this paper adds

Several studies have shown that the introduction of pictures on tobacco health warnings has increased the effectiveness of the warnings, but the added value of pictures in health warnings seems to decrease over time (wear-out).

- Evidence on wear-out is limited, and distinguishing between different types of wear-out is needed to understand if regularly changing the pictorial content of combined health warnings would help counteract the wear-out effects.

- This paper is, to the best of our knowledge, the first one which tests for the presence of general and content-specific wear-out effects that can occur due to repeated exposure to health warnings on tobacco products.

- The empirical results, based a on web experiment carried out in 10 European countries, show that smokers who have been regularly exposed to combined text+picture health warnings on tobacco products get used to the presence of pictures in general, as well as to the specific content of the pictures.

- The paper strengthens the evidence that pictorial health warnings are an effective tool for tobacco control policies and suggests that wear-out effects can be partially, but not fully, reversed by periodically introducing new pictures. 
over the same time period. ${ }^{30}$ This suggests that plain packaging might reduce or cancel wear-out effects.

Contributors EW and $\mathrm{Bd} \mathrm{d}^{\prime} \mathrm{H}$ jointly conceived the study, analysed the data and wrote the manuscript.

Funding The authors have not declared a specific grant for this research from any funding agency in the public, commercial or not-for-profit sectors.

Competing interests None declared.

Patient consent Not required.

Ethics approval London School of Economics Research Ethics Committee. Provenance and peer review Not commissioned; externally peer reviewed.

Open access This is an open access article distributed in accordance with the Creative Commons Attribution Non Commercial (CC BY-NC 4.0) license, which permits others to distribute, remix, adapt, build upon this work non-commercially, and license their derivative works on different terms, provided the original work is properly cited, appropriate credit is given, any changes made indicated, and the use is non-commercial. See: http://creativecommons.org/licenses/by-nc/4.0/.

\section{REFERENCES}

1 Noar SM, Francis DB, Bridges C, et al. The impact of strengthening cigarette pack warnings: Systematic review of longitudinal observational studies. Soc Sci Med 2016;164:118-29.

2 World Health Organisation. Framework Convention on Tobacco Control (FCTC). 2005. http://www.who.int/fctc/textl_download/en/

3 World Health Organisation. Guidelines for implementation of the who framework convention on tobacco control. 2013. http://www.who.int/fctc/treatyl_instruments/ adopted/guidelı_2011/en/

4 Hammond D, Fong GT, Borland R, et al. Text and graphic warnings on cigarette packages: findings from the international tobacco control four country study. Am J Prev Med 2007:32:202-9.

5 Borland R, Wilson N, Fong GT, et al. Impact of graphic and text warnings on cigarette packs: findings from four countries over five years. Tob Control 2009;18:358-64.

6 Hitchman SC, Driezen P, Logel C, et al. Changes in effectiveness of cigarette health warnings over time in Canada and the United States,2002-2011. Nicotine Tob Res 2014;16:536-43.

7 White V, Bariola E, Faulkner A, et al. Graphic health warnings on cigarette packs: How long before the effects on adolescents wear out? Nicotine Tob Res 2015;17:776-83.

8 Directive 2001/37/EU. Directive of the European Parliament and of the Council of 5 June 2001 on the approximation of the laws, regulations and administrative provisions of the Member States concerning the manufacture, presentation and sale of tobacco products. 2001. OJ L 194 (2001).

9 Decision 2003/641/EU. Decision of 5 September 2003 on the use of colour photographs or other illustrations as health warnings on tobacco packages, 2014.

10 Ratneswaran C, Chisnall B, Drakatos P, et al. A cross-sectional survey investigating the desensitisation of graphic health warning labels and their impact on smokers, non-smokers and patients with COPD in a London cohort. BMJ Open 2014;4:e004782.
11 Borland R, Yong HH, Wilson N, et al. How reactions to cigarette packet health warnings influence quitting: findings from the ITC Four-Country survey. Addiction 2009; 104:669-75.

12 Li L, Borland R, Yong $\mathrm{H}$, et al. Longer term impact of cigarette package warnings in Australia compared with the United Kingdom and Canada. Health Educ Res 2015:30:67-80.

13 Hammond D, Reid JL, Driezen P, et al. Pictorial health warnings on cigarette packs in the United States: an experimental evaluation of the proposed FDA warnings. Nicotine Tob Res 2013;15:93-102.

14 Thrasher JF, Arillo-Santillán E, Villalobos V, et al. Can pictorial warning labels on cigarette packages address smoking-related health disparities? Field experiments in Mexico to assess pictorial warning label content. Cancer Causes Control 2012;23 Suppl 1:69-80.

15 Hitchman SC, Mons U, Nagelhout GE, et al. Effectiveness of the European Union text-only cigarette health warnings: findings from four countries. Eur J Public Health 2012;22:693-9.

16 Hammond D, Thrasher J, Reid JL, et al. Perceived effectiveness of pictorial health warnings among Mexican youth and adults: a population-level intervention with potential to reduce tobacco-related inequities. Cancer Causes Control 2012;23 Suppl 1(Suppl 1):57-67.

17 Hammond D. Health warning messages on tobacco products: a review. Tob Control 2011;20:327-37.

18 O'Hegarty M, Pederson LL, Nelson DE, et al. Reactions of young adult smokers to warning labels on cigarette packages. Am J Prev Med 2006;30:467-73.

19 O'Hegarty M, Pederson LL, Yenokyan G, et al. Young adults' perceptions of cigarette warning labels in the United States and Canada. Prev Chronic Dis 2007:4:A27.

20 Yong $\mathrm{HH}$, Borland R, Thrasher JF, et al. Mediational pathways of the impact of cigarette warning labels on quit attempts. Health Psychol 2014:33:1410-20.

21 Maynard OM, Attwood A, O'Brien L, et al. Avoidance of cigarette pack health warnings among regular cigarette smokers. Drug Alcohol Depend 2014;136:170-4.

22 Directive 2014/40/EU. Directive of the European Parliament and of the Council of 3 April 2014 on the approximation of the laws, regulations and administrative provisions of the Member States concerning the manufacture, presentation and sale of tobacco and related products and repealing. OJL 2014. 127/1 (2014).

23 Bogliacino F, Codagnone C, Veltri GA, et al. Pathos \& Ethos: Emotions and Willingness to Pay for Tobacco Products. PLoS One 2015;10:e0139542.

24 Cohen J, Cohen P, West SG, et al. Applied Multiple Regression/Correlation Analysis for the Behavioral Sciences. 3rd ed. New Jersey: Lawrence Erlbaum Assoc Inc, 2002.

25 Gelman A, Hill J. Data Analysis Using Regression and Multilevel/Hierarchical Models. Cambridge: Cambridge Univ. Press, 2006.

26 Rogers WH. Regression standard errors in clustered samples. Stata Technical Bulletin 1993:13:19-23.

27 tobaccolabels.ca [Internet]. Waterloo: Tobacco labelling resource centre. c2014 http:// www.tobaccolabels.ca (cited 2014 Oct 24).

28 Noar SM, Hall MG, Francis DB, et al. Pictorial cigarette pack warnings: a meta-analysis of experimental studies. Tob Control 2016:25:341-54.

29 Rankin CH, Abrams T, Barry RJ, et al. Habituation revisited: an updated and revised description of the behavioral characteristics of habituation. Neurobiol Learn Mem 2009:92:135-8.

30 Swayampakala K, Thrasher JF, Yong HH, et al. Over-Time Impacts of Pictorial Health Warning Labels and their Differences across Smoker Subgroups: Results from Adult Smokers in Canada and Australia. Nicotine Tob Res 2018;20:888-96. 